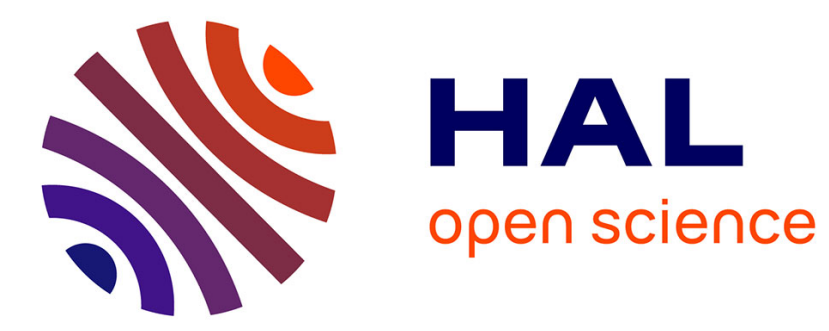

\title{
Adaptive responses to landscape disturbances: Empirical evidence.
}

Bruno Colas, Chris D Thomas, Ilkka Hanski

\section{To cite this version:}

Bruno Colas, Chris D Thomas, Ilkka Hanski. Adaptive responses to landscape disturbances : Empirical evidence.. Evolutionary Conservation Biology, 2004. hal-03496838

\section{HAL Id: hal-03496838 \\ https://hal.science/hal-03496838}

Submitted on 20 Dec 2021

HAL is a multi-disciplinary open access archive for the deposit and dissemination of scientific research documents, whether they are published or not. The documents may come from teaching and research institutions in France or abroad, or from public or private research centers.
L'archive ouverte pluridisciplinaire HAL, est destinée au dépôt et à la diffusion de documents scientifiques de niveau recherche, publiés ou non, émanant des établissements d'enseignement et de recherche français ou étrangers, des laboratoires publics ou privés. 


\section{EVOLUTIONARY RESPONSES TO LANDSCAPE FRAGMENTATION}

Bruno Colas ${ }^{1}$, Chris D. Thomas ${ }^{2}$, and Ilkka Hanski ${ }^{3}$

${ }^{1}$ Laboratoire d'Ecologie, UMR 7625, CC 237, Université de Paris VI, 7 quai SaintBernard, F-75252 Paris cedex 05, France.

${ }^{2}$ Centre for Biodiversity and Conservation, School of Biology, University of Leeds, Leeds, LS2 9JT, UK

${ }^{3}$ Metapopulation Research Group, Department of Ecology and Systematics, PO Box 17 (Arkadiankatu 7), FIN-00014 University of Helsinki, Finland

\section{Introduction}

Previous chapters of this book have examined the risks of extinction for small and/or isolated populations. We shall now try to see, with empirical data, how species and metapopulations can respond to habitat fragmentation. During the past 30 years, metapopulation biology has become recognised as an invaluable perspective in ecology, genetics and evolution (Olivieri et al. 1990), and a considerable body of theoretical and empirical research has been carried out (for reviews see Harrison and Hastings 1996; Hanski and Gilpin 1997; Hanski 1999).

The abundance of a species depends not only on the availability of habitats matching the ecological requirements of the species but also on the life history characteristics influencing local population persistence and colonization ability, that is its metapopulation dynamics (see Gyllenberg, Hanski and Metz). Colonisation ability in particular is critical, and it depends on traits related to migration and on the ability to establish a new population with a small propagule size (Box 1). Rapid colonisation may compensate for a low probability of local persistence (e.g., Van der Meijden et al. 1985). Besides determining colonization abilities, migration also affects local population viability, especially when local population dynamics is greatly influenced by spatially uncorrelated stochasticity (see Stacey and Taper 1992 for an example).

The evolved characters of populations, metapopulations and species also depend on rates of gene flow among populations and on extinction-colonisation dynamics (Olivieri et al. 1995; Storfer 1999). Migration creates gene flow that may result in outbreeding depression (e.g., Waser and Price 1989; Fenster and Galloway 2000; Quilichini et al. 2001) but also prevent local adaptations from evolving (Storfer 1999), and inbreeding and its associated deleterious effects to build-up (Table 1). Migration rate will itself evolve, and in a landscape that is characterized by long-term and large-scale stability, the metapopulation is expected to reach a large-scale steadystate, where selective processes operate at the local and metapopulation levels, and depend on the different demographic parameters, rates of migration, local population size, and extinction and colonization rates.

\section{The effects of landscape fragmentation}

The balances among the ecological processes and among the evolutionary processes in fragmented landscapes are likely to have been disrupted by the recent growth of human populations and the associated development that has altered land use patterns. Natural habitats have become more fragmented by intensive agriculture, forestry, urban development, etc. Properties of habitat fragments, such as their size, shape, quality and isolation, have become 
radically altered over large parts of the globe.

Habitat fragmentation has three major components, namely reduction of the pooled area of the habitat (habitat loss), reduction in the average fragment size, and an increase in the average distance between fragments (Wilcox and Murphy 1985, Andrén 1994).

The immediate consequences of habitat fragmentation are that the average size of local populations decreases and the average number of immigrants arriving at particular sites also decreases (Hanski 1999). Small isolated populations are more prone to extinction than large connected populations for various reasons including a greater impact of environmental and demographic stochasticities, Allee effects, and edge effects. At the level of the metapopulation, after habitat fragmentation, individual migrants have reduced chances of encountering a suitable site, which increases the rate of mortality during migration. In a metapopulation context, fragmentation may thus increase local extinctions and decrease colonisation rates, and, consequently, may doom a species to extinction (Hanski 1989).

Later consequences of fragmentation concern the genetic effects associated with smaller population size and lower migration. That leads to a higher rate of inbreeding (see Gaggiotti and Couvet). The deleterious effects related to inbreeding can impair significantly population survival (see Box 2). At the opposite, lower migration will allow enhanced possibilities of adaptation to marginal habitats (see Holt). Thus, the extent to which inbreeding will impair population survival depends on the relative importance of inbreeding depression and local adaptations (see discussion in Mills and Allendorf 1996).

\section{The aims of this chapter}

The effects of fragmentation have been much discussed in conservation biology (for a review see Hanski and Simberloff 1997). But how metapopulations and species may evolve after and cope with fragmentation is much less certain. Fragmentation will modify selective pressures on migration, depending on the previous consequences on demographic and genetic characters of the metapopulation. That leads to the possibility of many interactions.

The goal of this chapter is to show empirical evidence for evolutionary consequences of habitat fragmentation, and their effects on metapopulation viability. We will first examine the effect of fragmentation on migration (section 2) then a further complexity will be examined where local adaptations are also involved (section 3). Section 4 deals with the example of a threatened species, and its long-term evolution in a naturally highly fragmented landscape. In the final section, we attempt to summarize the knowledge concerning the consequences of habitat fragmentation in natural populations. 


\section{Response of migration to landscape fragmentation}

Predictions concerning the evolution of migration in response to fragmentation are presented in Box 3 (deeper explorations of the theoretical mechanisms involved are presented in the previous chapter). Different outcomes can occur, depending on the response to fragmentation of local population extinction, survival of migrants, and the proportion of empty patches. Keeping in mind these results, necessary to interpret observations, we will now examine empirical studies.

\section{a. Influence of patch isolation}

Effects of habitat patch isolation on migration rate have been described for populations of several butterflies. Dempster et al. (1976) and Dempster (1991) found that two species of butterflies undertook phenotypic changes in body morphology following habitat fragmentation and population isolation. For both the swallowtail butterfly, Papilio machaon, and the large blue, Maculinea arion, Dempster examined the morphology of museum specimens that had been collected over many years. Through time, the thorax shapes of both species became thinner in isolated populations. Furthermore, Dempster et al. (1976) showed that thin-thoraxed swallowtails flew more slowly than swallowtails with wide thoraxes. Since the thorax of a butterfly is almost entirely filled with flight muscles, Dempster suggested that these two butterfly species might have evolved reduced flight capacity following population isolation. Strong-flying individuals with fat, muscle-filled thoraxes would have tended to emigrate, whereas relatively puny insects would stay in the habitat where they had emerged (Table 2).

Body resources saved from the flight muscles could be allocated to reproduction, and this might be as important as, or more important than, selection on migration itself. Most of the resources allocated to reproduction in adult butterflies are located in the abdomen, and so it is important to assess whether isolated populations possess relatively large abdomens as well as small thoraxes. Museum specimens are not ideal for this purpose, for various reasons, including the unknown age and reproductive history of adults, and the weather conditions under which they developed, which influence thorax and abdomen shapes and weights. Therefore, it is better to measure the relative allocation of resources to different body parts in freshly emerged specimens, before they have flown, mated, fed and laid eggs. Thus, J.K.Hill, O.T.Lewis, D.Blakeley and C.D.Thomas (unpublished) followed-up Dempster's (1991) suggestion that British swallowtail butterflies had evolved smaller thoraxes, by rearing British and Spanish swallowtails, in a common environment in the laboratory. Spanish swallowtails are widely distributed, fly fast and occur in many habitats. Hill et al. confirmed that isolated British swallowtails have smaller relative thorax sizes and larger relative abdomen sizes than their more dispersive Spanish counterparts. It is difficult to prove that this difference is caused by habitat isolation rather than by some other difference between the two study populations, but habitat isolation is a plausible explanation (Table 2).

\section{b. Influence of patch size, in relation with other life-history traits}

In similar vein, Thomas et al. (1998) studied a third species of butterfly, Plebejus argus, in isolated metapopulations. Some of the metapopulations inhabited small and isolated fragments of heathland vegetation, whereas others inhabited much more extensive areas of heathland. Within each heathland, the butterflies themselves had quite localised distributions, being restricted to areas with high densities of mutualist ants (the caterpillars are tended and protected by ants, which obtain sugars and amino acid secretions from the caterpillars). In a large area of heathland, 
adult $P$. argus butterflies leaving their ant-enriched habitat would almost certainly find another area of suitable breeding habitat somewhere else within the heathland. In contrast, a wandering butterfly might be more likely to leave a small fragment of heathland vegetation completely, eventually perishing in the surrounding agricultural land. Surprisingly, butterflies reared in the common environment that originated from small heathland fragments were relatively large indicative of relatively strong flight capacity. This was the opposite of what was first expected: to find weak fliers in small heathlands. There are various reasonable explanations for this result, but one possibility is that large males might be better at defending mating territories - small males that were displaced from territories might be more likely to emigrate completely, the impact being greatest in small areas (Thomas et al. 1998; Table 2). The important lesson is that the evolution of flight ability and migration is often a complex compromise between different activities (adult feeding, mating, finding egg-laying sites, avoiding predators, as well as true migration), and any or all of these other activities may also be affected by habitat area and isolation.

Thomas et al. (1998) studied one metapopulation of Plebejus argus in more detail. This metapopulation inhabited a different type of vegetation, limestone grassland. In this case, all of the patches of habitat were within the migration range of at least one other patch, with a measured exchange rate of $1.4 \%$ per generation (Lewis et al. 1997). In this system, adult butterflies from small patches had relatively large thoraxes and small abdomens. Two equally plausible explanations are that 1) large-thoraxed individuals are capable of defending territories, so they can stay within small patches/territories whereas weedier adults are forced out of small patches, or that 2) small patches receive higher fractions of immigrants or have been recolonised more recently than large patches, such that small patches are populated mainly by strong-flying immigrants and by the offspring of immigrants. The first of these explanations predicts that migrants between patches are small-thoraxed individuals, whereas the second predicts that migrants between patches are large-thoraxed individuals. These alternative predictions have yet to be tested.

\section{c. Colonisation of new habitats}

In plant species of the Asteraceae family, Cody and Overton (1996) have shown that dispersal ability can evolve in a few generations only. They studied the evolution of pappus length of achenes on the mainland and in newly-established island populations in British Columbia. They showed that island populations were established by achenes with the longest pappus (increasing ability to disperse by wind) in the mainland populations. But once on an island, dispersal can be selected against, because islands are surrounded by an unfavourable habitat (the sea). After less than five generations since the establishment, pappus length was already significantly reduced in at least one species (Cody and Overton 1996).

One might expect the same sequence of events to take place in terrestrial habitat islands (Olivieri et al. 1990, 1995). In butterflies, there is some indication that colonising populations may indeed be characterized by large thoraxes and small abdomens, the opposite of the syndrome predicted for truly isolated populations. Dempster (1991) noted an increase in thorax width in Maculinea arion during a period of population expansion, and a reversal of the trend towards small thoraxes in isolated populations. Further evidence comes from common-environment rearings of colonising and non-colonising metapopulations of two other butterfly species. Human activities have generated empty habitat networks for the silver-spotted skipper butterfly, Hesperia comma (Thomas and Jones 1993). This butterfly is restricted to fragmented grasslands on calcareous soils in Britain, and it requires very short and sparse vegetation. Hesperia comma declined steeply when humans introduced the disease myxomatosis, which killed virtually all of 
the rabbits that had been responsible for maintaining the short turf favoured by this butterfly. This habitat rapidly became overgrown, and the skipper became rare and localised. More recently, the recovery of rabbits from myxomatosis has restored fragmented habitat networks for H. comma, which is gradually recolonising them. A metapopulation in East Sussex, characterised by large thoraxes and small abdomens, is rapidly expanding its distribution into an empty habitat network, whereas insects from a stable metapopulation elsewhere in southern England have relatively small thoraxes and large abdomens (Hill et al. 1999a).

The same pattern is seen in expanding populations of the woodland butterfly Pararge aegeria. This species is expanding is northern margin in Britain, almost certainly in response to anthropogenic climate warming (Hill et al. 1999b). The expansion is taking place in agricultural landscapes containing scattered woodlands, providing ample opportunity for repeated founder events and selection for increased dispersal rate. As predicted, the expanding northern population was found to possess larger thoraxes and small abdomens than a more stable population further south (Hill et al., 1999b; Table 2). Interestingly, the difference was much greater for female morphology (the colonising sex) than for males (Hill et al., 1999b) - male morphology is probably largely determined by mate location strategy and thermoregulation (van Dyck et al. 1997).

The above examples illustrate the complexity of potential responses to landscape pattern, resulting in both increased and decreased migration rate depending on the exact changes that take place in the landscape (Heino and Hanski 2001), and on the temporal and spatial scales observed. The impact of other traits and selection pressures on migration rate (mating strategy, predator evasion, etc.) further complicate the consequences of habitat fragmentation. Nonetheless, these examples do indicate that evolutionary changes in migration rates and in life history traits associated with dispersal are likely to be extremely common in modern landscapes. How often this is of practical concern is another matter. In any case, the average dispersal traits of organisms that survive in modern, fragmented landscapes are likely to be different from those of the original fauna and flora (Thomas 2000).

\section{The relationship between local adaptations, migration, and fragmentation}

Habitat fragmentation has the potential to disrupt any former balance between gene flow and local selection. We might initially expect local adaptations to increase following habitat fragmentation and isolation, because locally-adapted traits will no longer be diluted by gene flow from populations adapted to other habitats (Dhondt et al. 1990; Storfer 1999). However, in the long term, successful colonists may be favoured at the metapopulation-level, a situation analagous to that already described for the evolution of migration rate. Selection within individual populations may favour local specialists, but generalists may be more successful colonists. Evolutionary changes may also take place as a result of the changing qualities of habitat remnants, caused by disturbance, or by changes in the identities of other species inhabiting the same fragments. Some species may develop adaptations to anthropogenic habitats outside of natural vegetation fragments, while continuing to exchange genes with populations still residing in nearby natural habitats. In the extreme, this could disrupt local adaptations to natural habitats.

\section{a. Adaptation to local hosts}

An example of reciprocal influence of extinction-colonization dynamics in a highly fragmented landscape and the evolution of host plant preference in the butterfly Melitaea cinxia is 
provided by the recent study of Hanski and Singer (2001). Melitaea cinxia has two larval host plants in the Åland Islands, SW Finland, Plantago lanceolata and Veronica spicata. A distinct west-east gradient exists in the relative abundances of the two host plants, and this gradient is parallelled by a gradient in genetically determined host plant preference by female butterflies within a distance of $30 \mathrm{~km}$ (Kuussaari et al. 2000). Such small-scale adaptation to the regionally more abundant host plant raises an interesting question about metapopulation dynamics. Assume that butterflies in a particular region have evolved a preference for $V$. spicata (or vice versa). Host species composition varies from one habitat patch to another, and though most patches in some region are dominated by $V$. spicata, some patches have only $P$. lanceolata. Given the evolved host plant preferences in female butterflies, we may ask whether the host plant composition of habitat patches influences metapopulation dynamics? The answer turned out to be conclusively yes. Habitat patches that are dominated by the host plant to which the metapopulation in a given region has adapted have a substantially higher rate of colonization than patches dominated by the regionally rare alternative host plant (Hanski and Singer 2001). The effect of female host preference on colonization probability is probably caused by the effects of female preference on emigration and immigration in relation to the local host plant composition rather than by spatial variation in larval performance.

We may also ask the reverse question, does extinction-colonization dynamics influence the evolution of host plant preference? Modelling results and the empirical results indicated such an effect, as the model-predicted average host plant preference in a particular habitat patch network explained a significant amount of among-network variation in preference (Hanski and Heino, in prep.). Thus, in this example colonization probability depends on a genetically determined trait of colonizers, which is selected both at the level of local populations and at the level of the metapopulation. Other studies have elucidated how local adaptation and gene flow promote genetic variation in metapopulations in general (Karban 1989; Wade 1990; Antonovics et al. 1994) and how local adaptation may be influenced by gene flow (Holt 1995; Dias 1996; Pulliam 1996). The M. cinxia example suggests that gene flow and the establishment of new populations may also be influenced by local adaptation.

\section{b. Adaptation to anthropogenic habitats}

One form of habitat change is represented by the arrival of new species. When the European plant Plantago lanceolata arrived in North America, it spread rapidly, and became established in irrigated meadows along the eastern slopes of the Sierra Nevada mountains. The native checkerspot butterfly Euphydryas editha was already present in the area. The caterpillars of this butterfly fed naturally on Collinsia parviflora, a plant that shares certain iridoid glycosides with P. lanceolata. Some females started to lay batches of eggs on P. lanceolata (Thomas et al. 1987). Larval survival was higher on the introduced plant than on the native $C$. parviflora, and female choice of host plant had a genetic basis (Singer et al. 1988). Over a ten-year period, the proportion of females laying on $P$. lanceolata was observed to increase, resulting in the exclusion of $C$. parviflora from the diet in at least one population (Singer et al. 1993). This is either a great bonanza for this rare butterfly - Plantago lanceolata is widespread - or a serious risk. Within the study region, $P$. lanceolata is mostly restricted to irrigated land. The newly-evolved Plantagofeeding population might have doomed itself to extinction if irrigation ceases to be economic.

Logging of native forests, and allowing them to regenerate, is another globally widespread form of habitat modification. Logging in a different part of the Sierra Nevada mountains, in California, provided another new opportunity for another metapopulation of Euphydryas editha. This metapopulation was quite different from the one just described. The butterflies naturally laid 
their eggs on Pedicularis semibarbata (mainly) and Castilleja disticha, two species of Scrophulariaceae: the population was restricted to natural granitic outcrops in an otherwise forested region (Singer 1983). Logging created major new openings in the forest, and rendered a third species of Scropulariaceae, Collinsia torreyi, suitable as a host plant (following disturbance, the plant grew to be sufficiently large for the caterpillars to complete their life cycle on the plant). Huge populations of the butterfly established in these new clearings (Singer 1983; Thomas et al. 1996). Vast numbers of butterflies emerged in the logged habitat and flew back to the natural habitat, resulting in intense competition in the natural habitat. This set up asymmetric gene flow from the logged habitat to the natural habitat. Adaptations to the new environment started to develop (acceptance of $C$. torreyi plants by females), but they came at the cost of reduced level of adaptation (reduced preference for Pedicularis and Castilleja) in nearby populations still inhabiting the natural rocky outcrops (Singer et al. 1993; Singer \& Thomas 1996; Thomas et al. 1996).

If new populations in anthropogenic habitat are at risk of extinction, reduced levels of adaptation to undisturbed environments are potentially worrying. In this case, forest clearings become overgrown eventually, and populations would be bound to become locally extinct. But something much more dramatic happened. An aseasonal summer frost killed all of the Collinsia torreyi plants in the forest clearings, without harming either of the natural host plants in the rocky outcrops. Euphydryas editha larvae were resistant to the frost, but larvae in the forest clearings starved because Collinsia had died, and a year later all clearing populations of the butterfly had become extinct. Fortunately, the butterflies survived in their natural habitat. Both of these examples on E. editha illustrate how evolutionary adoption of habitats that are created and maintained by humans both enable species to cope with human activities and simultaneously put them at risk from future changes in land management. Future changes in management practices and agricultural economics may take place too fast for the species to cope, a serious problem once the original adaptations to native habitats have been lost. This is a clear example of the advantages of niche conservatism (see further discussion in the chapter of Holt).

\section{Habitat fragmentation and diversity: the example of Centaurea species in southern France}

Studies of metapopulation dynamics of species living in naturally highly fragmented habitats, like in the case of Centaurea corymbosa (Asteraceae) can improve the understanding the long-term consequences of habitat fragmentation.

\section{a. A slow metapopulation dynamics}

The combined results on population genetic structure, achene dispersal distances, reproductive system, seed sets, and survival following experimental introductions have allowed us to get a general view of the species' population biology: the unique metapopulation of C. corymbosa has slow dynamics (see Box 4). Many suitable sites (cliffs) are available near the extant populations, as shown by the experimental introductions, but remain empty because of very low colonisation ability (Fig.1). Achene dispersal by gravity and wind is restricted to a few tens of centimeters from the mother plant. This may be due to the landscape structure, i.e. unsuitable habitat surrounding the existing populations, which selects against dispersal (Olivieri et al. 1995; Cody and Overton 1996): any achenes that leave the cliff will almost certainly arrive in a vegetation where they will be unable to grow/compete successfully. One species of ant (Crematogaster scutellaris) disperses some C. corymbosa seeds but probably not more than 
several meters, and, in any case, cannot bring a seed from one cliff to another. In addition to a low dispersal ability, Colas et al. (1997) suggested that the low colonisation ability is reinforced by semelparity and self-incompatibility. Indeed, reproductive success of an individual plant mainly depends on neighbours, and the closer they are, the higher the probability that they will set seeds (Colas et al., 2001). If, by chance, a few seeds would disperse longer distances to a suitable cliff, germinate and grow up to flowering plants, they are likely to die without giving rise to any surviving progeny unless they would flower in the same year and be compatible.

There are convincing examples that bottlenecks may induce the dissolution of systems (heterostyly, self-incompatibility) avoiding selfing in plants (Reinartz and Les 1994; Eckert et al. 1996; Barrett 1998). It seems clear also that founder events might promote the evolution of dispersal (Cody and Overton 1996). But, in the absence of colonisation, it seems unlikely that these traits will evolve in C. corymbosa. Therefore, this species seems to be captured in a vicious circle (Fig. 1), an evolutionary spiral that prevent colonisation and might lead the species to extinction. However, on the basis of historical data (Colas et al., 1997), 5 populations were already known 100 to more than 200 years ago, and none has disappeared. Since mean generation time is about 5.5 years (Colas et al., in prep.), this represents 20 to 40 generations. The populations are very small, but the extinction rate may be no greater than the rate of colonisation of new cliffs in this quite stable habitat. Thus, C. corymbosa could be well adapted to its fragmented habitat.

\section{b. Metapopulations and species diversity}

Centaurea corymbosa belongs to the Maculosae group which comprises 23 taxa (species an subspecies) of which most are narrowly endemic (Tutin et al. 1976). Many taxonomic groups within the huge Centaurea genus (500 species with lots of subspecies around the Mediterranean, Bremer 1994) show this pattern: one widespread and several narrowly distributed endemics. Fréville et al. (1998) compared allozyme diversity in C. corymbosa and two related taxa sharing the same type of habitat in other places of southern France: the widespread C. maculosa maculosa and C. maculosa albida, occuring in only one population of about 200 individuals. Diversity of the two endemic taxa represented a sample of the diversity of the widespread one, and the former are probably derived from the latter. As in $C$. corymbosa, high allozymic differentiation was found among populations of $C$. maculosa, but the amount of differentiation among populations of different taxa was not different from the amount of differentiation among populations within taxa. Fréville et al. (1998) suggested that ecological specialisation following bottlenecks or founder effects associated with colonisation events in C. maculosa maculosa resulted in the establishment of new taxa. Although probably very rare, long-distance achene dispersal may occur in these species by adhesion of the barbed and sticky bristles in the pappus to sheep or to the feathers of birds. In the Massif de la Clape, there are several cliffs where rocks occupied by C. corymbosa are also those where pellets from the owl Bubo bubo can be found (Colas 1997).

Habitat fragmentation may actually be the cause of high species diversity in Centaurea species, as well as in other mediterranean plants (see review by Thompson 1999). Some colonisation, followed by isolation, would permit divergence (adaptive or not), potentially generating diversity. In the cliff-dwelling Centaurea species, new species might be established as quickly as other species go extinct. In this case, rather than allocating all conservation efforts to the conservation of one particular species that may naturally go extinct, it might be a better idea to preserve habitat diversity in order to allow species to diverge, evolve, and die. But of course, this is a long-term, evolutionary perspective that managers may not find appealing. However, one should seriously consider the role that fragmentation may play in the generation of diversity, as 
well as in the decline of genetic diversity.

Interestingly, it appears from these studies on Centaurea species that defining a metapopulation depends on the scales of space and time considered. One may consider C. corymbosa, as we stated above, as a unique metapopulation made of 6 panmictic populations among which restricted (medium distance) gene flow occurs and with very slow extinctioncolonisation dynamics (probably observable over tens to hundreds of generations). Second, it appears from a demographic study using 40 permanent quadrats on rocks since 1994, that understanding the persistence of each population necessitates to consider the processes of migration and extinction and (re-)colonisation among quadrats (i.e., patches of plants; Colas et al., in prep.). Every patch may persist one to several generations, and achene migration between adjacent suitable rocks (a few meters apart) occurs by gravity, wind or ant dispersal. Thus, at a time scale of a few generations, one may consider each of the six panmictic unit as an isolated metapopulation itself, with extinction-colonisation processes occuring among patches, due to the effects of environmental and demographic stochasticity and to ordinary short distance dispersal (Colas et al., in prep.). At last, one might consider that the Maculosa group of Centaurea species is a kind of meta-species with rare long distance dispersal events leading to isolated populations that may differentiate from each other through drift and/or heterogeneous selection. Extinctioncolonisation processes at this large scale in space and time is closely related to evolutionary processes of speciation and to species' extinction.

\section{Concluding comments}

Almost all habitats have changed dramatically over recent decades and centuries, throughout the world. Changes in directional selection, new evolutionary optima and changes in the balance between gene flow and selection must be widespread phenomena. The example on Centaurea species described in section 4 suggests that natural fragmentation is probably an important cause of species diversity. However, this is a long-term evolutionary consequence of stable landscape heterogeneity. As we suggested in section 3 with the butterfly examples, recent changes in land use might be too fast for any evolutionary processes to occur. A key factor in the future studies of the effects of fragmentation will probably be whether fragmentation occurred progressively or suddenly, then allowing evolution or not.

The examples in this chapter illustrate some evolutionary consequences of these changes. The response of migration rates to fragmentation is idiosyncratic, depending on how local extinction or fitness of migrants vary with patch size. Local adaptation have mixed effects on metapopulation viability, as they might reduce colonisation abilities, as well as migration, in particular between different habitats. Response can be inefficient, because there are many constraints that prevent the metapopulation to respond optimally to landscape changes, as shown by the interaction between local adaptations and migration in butterflies. A common feature of most relevant studies is the large number of processes involved. Further understanding of the evolutionary responses to fragmentation in terms of inbreeding, local adaptation, or migration will be necessary to predict the effect that fragmentation can have on the different species present in a landscape.

It would probably be utopian to think that we will be able to determine critical thresholds for habitat fragmentation above which most of biodiversity can be conserved in a landscape. First, the relevant scale at which habitat fragmentation becomes important depends on the size of the home range of the species, which varies from a few $\mathrm{cm}^{2}$ to several $\mathrm{km}^{2}$ (Mönkkönen and Reunanen 1999). Second, minimum patch areas for viable local populations and maximum 
isolation distances to allow colonization are species-specific, since they depend on many lifehistory traits. Third, a landscape is not always made of suitable and unsuitable patches and intermediate habitats may serve as corridors for migration to occur. Levin (1995) illustrated the role of plant outliers for gene flow among populations. Depending on the habitat specificity of the species, the matrix surrounding a particular patch may be usable or completely hostile and impossible to cross. Fourth, the effects of fragmentation remain to be understood.

A better understanding of the ecological, genetic and evolutionary issues related to thresholds for long-term persistence in fragmented landscapes remains one of the big challenges for conservation biology, due to its complexity, but also to its relevance, as it concerns a large portion of remaining biodiversity.

Acknowledgements. Particular thanks to Jane Hill. I.Hanski and C.D.Thomas were supported by the TMR FRAGLAND network. Thanks to editors who extensively revised our manuscript, and to I. Olivieri and H. Fréville for their comments. 
Box 1: Factors involved in species distribution and abundance:

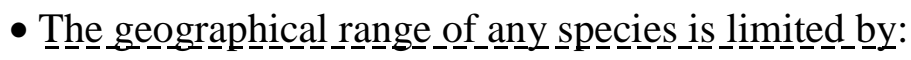

$\rightarrow$ The availability of sites where the required ecological conditions are met.

$\rightarrow$ The species ability to colonise these suitable sites.

(Gaston, 1994)

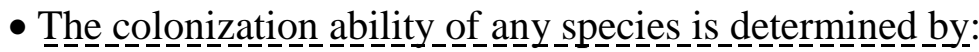

$\rightarrow$ Its dispersal ability.

$\rightarrow$ Its ability to establish a population from one or a few individuals.

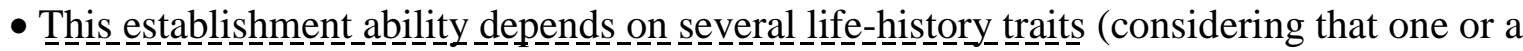
few colonising individuals reached an unoccupied suitable site, i.e. within which a population may occur given the ecological niche of the species):

$\rightarrow$ The reproductive system. For example, an inbreeding species or a plant species able to reproduce vegetatively will colonize more easily a new site from one or a few individuals than a strictly outbreeding species.

$\rightarrow$ The life cycle. For example, an iteroparous colonizer will have more chance to give offspring than a semelparous one. 


\section{Box 2. Inbreeding depression in the metapopulation of Melitaea cinxia}

The case study of a butterfly metapopulation living in a highly fragmented landscape has recently demonstrated genetic causes of population extinction. The large metapopulation of Melitaea cinxia in Finland consists of some hundreds of mostly very small local populations (Hanski 1999). Local populations have a high risk of extinction for many reasons, including demographic and environmental stochasticity and parasitism. The caterpillars live in large sibgroups, and often there is just one group of full sibs in a population. Mating amongst close relatives must therefore occur commonly in local populations. Inbreeding reduces heterozygosity and if inbreeding depression increases the risk of extinction, we would expect that, other things being equal, reduced heterozygosity is associated with an elevated risk of population extinction.

Saccheri et al. (1998) tested this prediction by genotyping a sample of butterflies from 42 local populations, of which seven went extinct in one year. Previous studies had shown that populations most likely to go extinct are characterized by small size, they are isolated (small numbers of butterflies in the neighboring populations, hence no rescue effect), and the habitat patch has a low density of nectar flowers (which increases emigration and decreases immigration). In their study, Saccheri et al. (1998) found that, in addition to these ecological factors, the level of heterozygosity in the population also made a highly significant contribution to the model explaining the observed extinctions. A recent experimental study by Nieminen et al. (2001) has confirmed that inbreeding indeed increases the risk of local extinction in this species. Laboratory studies have shown that inbreeding affects several fitness components in M. cinxia, including egg hatching rate, the weight of post-diapause larvae, pupal period (inverse relationship), and adult longevity (Saccheri et al. 1998; Haikola et al., 2001). Just a single round of brother-sister mating, which must occur commonly in the small populations in the M. cinxia metapopulation, was sufficient to reduce egg hatching rate by ca $30 \%$.

These results suggest that this metapopulation maintains a large genetic load. Apparently, selection against deleterious recessives exposed by local inbreeding is relatively inefficient, most likely due to high probability of fixation of slightly deleterious alleles in small populations and gene flow among neighbouring small local populations. This study was the first to demonstrate an effect of inbreeding on the extinction of natural populations. It remains an open question how widespread inbreeding-caused extinctions are in metapopulations in general. 


\section{Box 3: Predicting the migration response to landscape fragmentation}

Generally, migration is locally selected against because the probability of finding favourable breeding conditions is often higher while remaining in the natal patch rather than moving elsewhere. But, at the level of the metapopulation, migration can be selected for if the turnover rate of populations is sufficiently high: the increased availability of empty habitat patches, generated by local extinctions, may lead to a metapopulation-wide increase in migration rate (Olivieri et al. 1995; Leimar and Norberg 1997). This is known as the metapopulation effect (Olivieri and Gouyon 1997, see Ferrière). However, its general validity has been questioned recently (e.g. Ronce et al. 2000).

Heino and Hanski (2001) have constructed an individual-based simulation model that can be used for studying the evolution of migration rate in real landscapes with particular spatial configurations of the suitable habitat. Individual-based models have their own problems, in particular large number of model assumptions and parameters, and it is difficult to arrive at conclusive predictions via simulations. The authors were able to use two other models as building blocks of the evolutionary model, and the sub-models (on adult movements: Hanski et al. 2000, and on extinction-colonization dynamics: Hanski 1994) can be parameterized.

Heino and Hanski (2001) further parameterized their individual-based model of the evolution of migration comparing two closely related species of checkerspot butterflies, Melitaea cinxia and M. diamina. Using these parameter values, but allowing the emigration rate parameter to evolve in the model, they run the model in the real landscape for M. diamina and predicted a value of 0.106 (standard deviation 0.006) for this parameter (the parameter gives the daily probability of leaving a habitat patch of $1 \mathrm{ha}$ ). This value does not differ significantly from the value estimated in an empirical mark-release-recapture study $(0.130,95 \%$ confidence limits 0.104 and 0.171; Hanski et al. 2000). The great advantage of the model of Heino and Hanski (2001) is that it allows quantitative predictions to be made both for particular individual habitat patches as well as for networks of patches. It remains a great empirical challenge to collect sufficient data to test such model predictions.

Heino and Hanski (2001) found that if the primary consequence of habitat fragmentation is to increase local extinction risk due to decreased local population sizes, the evolutionary response was increased migration rate. If the quality of the matrix habitat deteriorates, leading to increased mortality during migration, a more complex evolutionary response was detected. In this case, as long as habitat patch occupancy did not decrease greatly with increased migration mortality, reduced migration rate evolved. However, once mortality became so high that empty patches remained uncolonized for a long time, evolution tended to increase migration rate, essentially because of the 'metapopulation effect' referred to above (see also Leimar and Norberg 1997). Heino and Hanski (2001) present scenarios in which the increased migration rate in response to habitat fragmentation leads to an 'evolutionary rescue', that is, a persisting metapopulation if evolution of migration rate is allowed for, but metapopulation extinction if no evolution is allowed to occur. 
Box 4: Natural history and genetic structure of Centaurea corymbosa:

\section{MAP}

Centaurea corymbosa is a self-incompatible, monocarpic perennial plant, endemic to a tiny $3-\mathrm{km}^{2}$ area situated within a $50-\mathrm{km}^{2}$ limestone plateau (Massif de la Clape) in southern France (Colas et al. 1996). Centaurea corymbosa lives in clefts of rocks on the top of cliffs with a very open vegetation and almost no soil. Apparently, it cannot stand competition: no plant can be found either on the plateau, in the middle of the garrigue, or in the pinewood, down in the depressions. Over all the 6 extant populations, 350 to 650 flowering plants were counted per year from 1994 to 2000 (from 5 to 250 per year per population). Each population is geographically clearly delimited.

Although populations are only 0.3 to $2.3 \mathrm{~km}$ apart, gene flow is very restricted among them, given the very strong genetic differentiation observed on allozymes (Colas et al. 1997) and on microsatellites (Fréville et al., 2001). The correlation between geographic and genetic distances among populations suggests that gene flow occurs mainly between adjacent populations. Population genetic structure for quantitative traits was similar to genetic structure for molecular markers (Petit et al. 2001), suggesting the absence of heterogeneous selection among populations (see Bonnin et al. 1996 and the chapter of Gaggiotti for a discussion on the relationship between neutral and selected characters concerning population genetic differentiation).

Although populations may stretch out along $670 \mathrm{~m}$, each population can be considered as a panmictic unit (no departure from Hardy-Weinberg expectations). This is the consequence of pollen dispersal within populations where about $20 \%$ of mating pairs are separated by more than $50 \mathrm{~m}$, as shown by paternity analyses (Hardy et al., submitted). But the amount of pollen dispersed to long distances is not sufficient to prevent the lower fertilization rate of ovules of isolated flowering plants compared to plants situated in dense patches (Colas et al. 1997, 2001). Pollen flow seems maily limited by gaps of unoccupied pieces of land between populations. 
Table 1. Some examples suggesting deleterious genetic effects associated with higher levels of fragmentation in natural populations

\begin{tabular}{|l|l|l|}
\hline $\begin{array}{l}\text { Unfavorable traits of small } \\
\text { populations }\end{array}$ & Species & Reference \\
\hline $\begin{array}{l}\text { Lower survival } \\
\text { Lower developmental homeostasis }\end{array}$ & Bufo bufo & $\begin{array}{l}\text { Hitchings and } \\
\text { Beebee 1998 }\end{array}$ \\
\hline $\begin{array}{l}\text { Lower larval survival } \\
\text { Lower larval growth rate } \\
\text { variation }\end{array}$ & $\begin{array}{l}\text { Salvia pratensis } \\
\text { Scabiosa columbaria }\end{array}$ & Rowe et al. 1999 \\
\hline $\begin{array}{l}\text { Lower seed size } \\
\text { Lower germination success } \\
\begin{array}{l}\text { Higher susceptibility to } \\
\text { environmental stress }\end{array}\end{array}$ & $\begin{array}{l}\text { Ipomopsis aggregata } 1991 \\
1995\end{array}$ \\
\hline $\begin{array}{l}\text { Lower survival } \\
\text { Hentianella germanica }\end{array}$ & $\begin{array}{l}\text { Fischer and Matthies } \\
1998\end{array}$ \\
\hline
\end{tabular}


Table 2. Observed traits associated with habitat characteristics in several species of butterflies (see text for details).

\begin{tabular}{|c|c|c|c|}
\hline $\begin{array}{l}\text { Habitat } \\
\text { characteristics }\end{array}$ & Observed butterfly traits & $\begin{array}{l}\text { Possible explanatory } \\
\text { selective pressure }\end{array}$ & Species (reference) \\
\hline \multirow[t]{2}{*}{ Isolated patches } & Small thoraxes & \multirow{2}{*}{$\begin{array}{l}\text { Selection against } \\
\text { dispersal ability }\end{array}$} & $\begin{array}{l}\text { Papilio machaon, Maculinea } \\
\text { arion (Dempster et al. 1976; } \\
\text { Dempster 1991) }\end{array}$ \\
\hline & $\begin{array}{l}\text { Small thoraxes } \\
\text { compared to abdomens }\end{array}$ & & $\begin{array}{l}\text { Papilio machaon (Hill et al., } \\
\text { unpub.) }\end{array}$ \\
\hline Small patches & Large thoraxes & $\begin{array}{l}\text { Selection for the ability } \\
\text { to defend mating } \\
\text { territories }\end{array}$ & $\begin{array}{l}\text { Plebejus argus (Thomas et al. } \\
\text { 1998) }\end{array}$ \\
\hline New habitats & $\begin{array}{l}\text { Large thoraxes } \\
\text { compared to abdomens }\end{array}$ & $\begin{array}{l}\text { Selection for } \\
\text { dispersal/colonising } \\
\text { ability }\end{array}$ & $\begin{array}{l}\text { Hesperia comma, Pararge } \\
\text { aegeria (Hill et al. 1999) }\end{array}$ \\
\hline
\end{tabular}




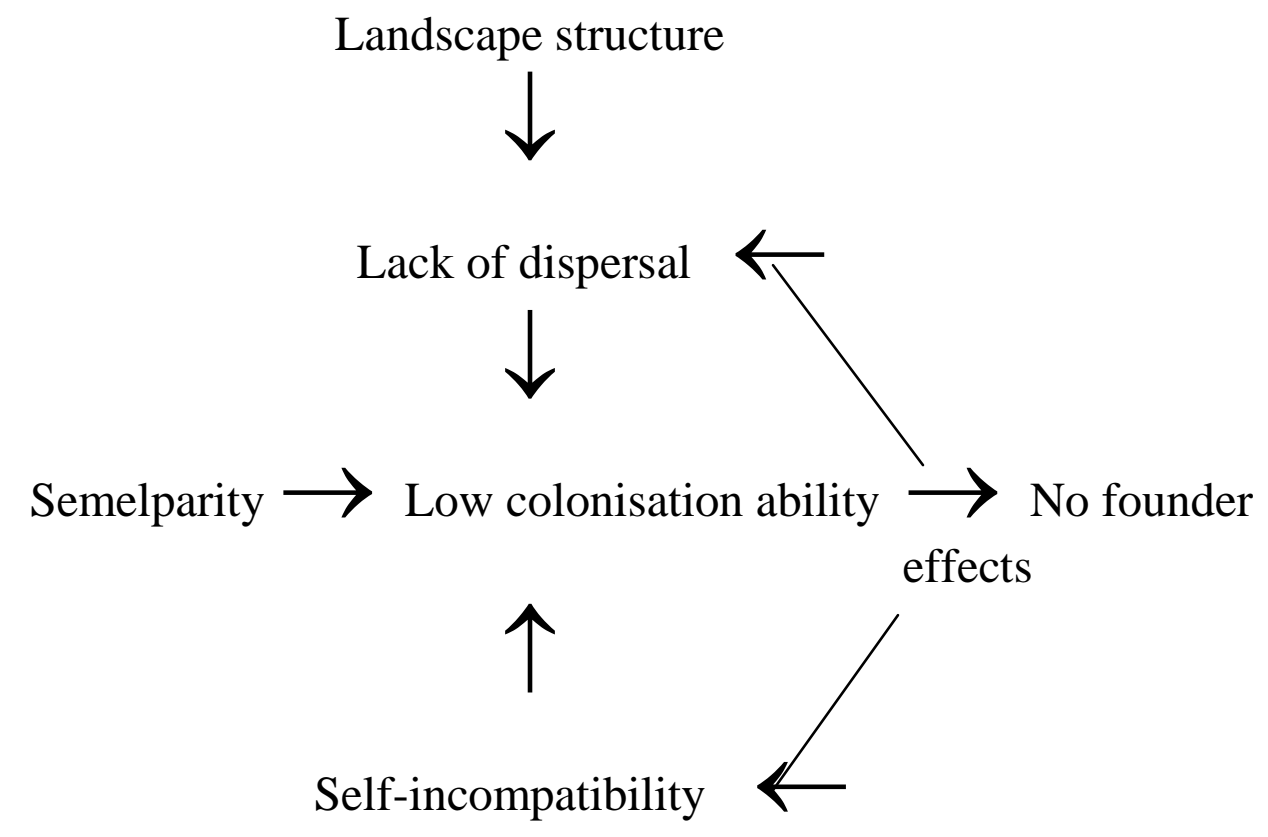

Fig. 1. Factors selecting against colonisation ability of Centaurea corymbosa. 